\title{
Large-Scale Circulation Anomalies Associated with Extreme Heat in South Korea and Southern-Central Japan
}

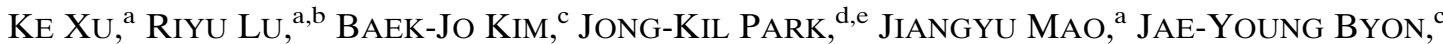 \\ RUIDAN CHEN, ${ }^{\mathrm{f}}$ AND EUN-BYUL KIM ${ }^{\mathrm{d}, \mathrm{e}, \mathrm{g}}$ \\ ${ }^{\text {a }}$ State Key Laboratory of Numerical Modeling for Atmospheric Sciences and Geophysical Fluid Dynamics, Institute of Atmospheric \\ Physics, Chinese Academy of Sciences, Beijing, China \\ ${ }^{\mathrm{b}}$ College of Earth and Planetary Sciences, University of the Chinese Academy of Sciences, Beijing, China \\ ${ }^{\mathrm{c}}$ Applied Meteorology Research Division, National Institute of Meteorological Sciences, Jeju-do, South Korea \\ ${ }^{\mathrm{d}}$ Department of Environmental Engineering, Inje University, Gimhae, South Korea \\ ${ }^{\mathrm{e}}$ Atmospheric Environment Information Research Center, Inje University, Gimhae, South Korea \\ ${ }^{\mathrm{f}}$ School of Atmospheric Sciences, Sun Yat-sen University, Guangzhou, China
}

(Manuscript received 27 July 2018, in final form 28 December 2018)

\begin{abstract}
The large-scale circulation anomalies associated with extreme heat (EH) in South Korea and southern-central Japan are examined using data during the time period 1979-2016. Statistical analysis indicates that EH days in these two regions are concentrated in July and August and tend to occur simultaneously. These EH days are therefore combined to explore the physical mechanisms leading to their occurrence. The composite results indicate that the anomalous atmospheric warming during EH days is dominantly caused by a significant subsidence anomaly, which is associated with a deep anomalous anticyclone over East Asia. Further investigation of the evolution of circulation anomalies suggests that the anomalous anticyclone over East Asia related to EH is primarily initiated by wave trains originating from upstream regions, which propagate eastward along the Asian westerly jet in the upper troposphere. These wave trains can be categorized into two types that are characterized by the precursor anticyclonic and cyclonic anomalies, respectively, over central Asia. The distinction between these two types of wave train can be explained by the wavenumbers of the Rossby waves, which are modulated by both the intensity and the shape of the Asian westerly jet as the background basic flow.
\end{abstract}

\section{Introduction}

Global climate change has strongly increased the worldwide frequency of extreme heat $(\mathrm{EH})$ in recent decades (e.g., Meehl et al. 2000; Griffiths et al. 2005; Choi et al. 2009; IPCC 2013; Kim 2013; E.-B. Kim et al. 2014). The damage caused by $\mathrm{EH}$, including socioeconomic losses and human disease, are well known (e.g., Easterling et al. 2000; Tan et al. 2007; Luber and McGeehin 2008; Park et al. 2008; Kim 2013). South Korea and southerncentral Japan are frequently affected by EH, which are projected to increase in frequency in the future (Boo et al. 2006; Nakano et al. 2013; Lee 2017). An in-depth understanding of the physical mechanisms of $\mathrm{EH}$ is therefore urgently required to mitigate their effects.

\footnotetext{
${ }^{\mathrm{g}}$ Current affiliation: R\&D Innovation Center, National Disaster Management Research Institute, Ulsan, South Korea.
}

Corresponding author: Ke Xu, xuke@mail.iap.ac.cn
South Korea and southern-central Japan are both influenced by the East Asian monsoon during the boreal summer (Tao and Chen 1987). Climatologically, a quasistationary rainband extends northeastward from the Yangtze River valley of China to South Korea and southern-central Japan in mid-June, signifying the onset of the rainy season (called changma in South Korea and baiu in Japan), which then persists until mid-July (e.g., Kawamura and Murakami 1998; Byun and Lee 2002; Ding and Chan 2005; Choi et al. 2012). As the rainy season ends, EH days increase drastically in South Korea and southerncentral Japan and occur frequently until late August (Lee and Lee 2016; also Fig. 2). During this peak period, EH days appear simultaneously in these two regions, and we therefore combined them to explore the physical mechanisms leading to their occurrence.

Previous studies have shown that the types of atmospheric circulation responsible for $\mathrm{EH}$ vary in different regions (e.g., Black et al. 2004; García-Herrera et al. 2005; Lau and Kim 2012; Loikith and Broccoli 2012; 
Chen and $\mathrm{Lu}$ 2015). For instance, Chen and $\mathrm{Lu}$ (2015) compared the types of circulation related to $\mathrm{EH}$ in five subregions of eastern China and identified three distinct categories. $\mathrm{EH}$ in two adjacent subregions of eastern and western North China at the same latitudes as South Korea and southern-central Japan is caused by different circulation anomalies: an anomalous anticyclone and foehnrelated northwesterly winds, respectively. The spatial variability of the types of circulation related to $\mathrm{EH}$ - which may result from differences in topography, surface conditions or climatology-indicates the need to carry out specific studies on the types of circulation responsible for $\mathrm{EH}$ in South Korea and southern-central Japan.

Previous research has suggested that an enhancement of the North Pacific subtropical high favors the occurrence of EH in South Korea and Japan, although this was derived by analyzing single extreme examples that occurred in 2004 (Enomoto et al. 2009) and 2013 (Imada et al. 2014; Y.-J. Kim et al. 2014). Several studies have concentrated on $\mathrm{EH}$ on the mesoscale (Takane and Kusaka 2011; Mori and Sato 2014; Takane et al. 2014). For instance, Takane et al. (2014) analyzed the EH in Tokyo and categorized the related patterns of surface pressure into three major types: a trough around central Japan, a south high-north low pattern, and an east high-west low pattern. However, their conclusions can only be applied in a small region near the selected station. By contrast, our study focused on large-scale EH events because they cause more extensive and heavier damage and are more closely related to large-scale circulation patterns. Sufficient numbers of EH samples are considered to perform a comprehensive statistical investigation of the circulations responsible for $\mathrm{EH}$.

Research into the evolution of circulation before the occurrence of EH will give a better understanding of the formation of EH-related circulations and has practical significance in improving their prediction. For instance, Chen et al. (2016) found that the anticyclonic-cyclonic circulation pattern, a feature of $\mathrm{EH}$ in southern China, originates from a quasi-biweekly wave train that forms over the tropical western Pacific. Gao et al. (2018) identified three types of precursory circulation for heat waves in the Yangtze River valley of China: an upper-level wave train migrating from eastern Europe; a lower-level wave train emanating from the tropical western North Pacific; and double wave trains originating, respectively, from eastern Europe at upper levels and from the tropical western North Pacific at lower levels. Enomoto et al. (2009) showed that the intensification of an anticyclone, which was responsible for the heat wave in Japan during July 2004, was influenced by the propagation of a Rossby wave packet along the subtropical jet. However, whether this is a common phenomenon is unclear because the result was obtained based on only one example. We also explored the evolution of

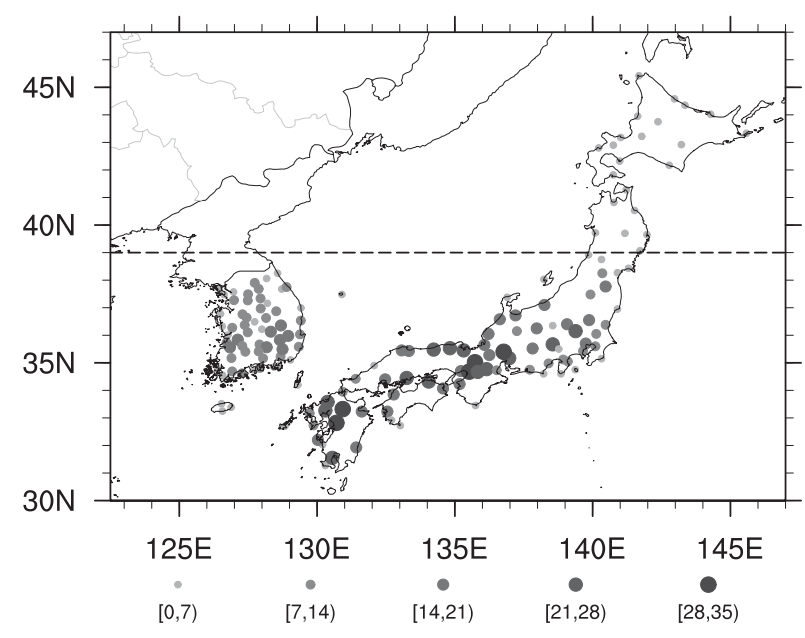

FIG. 1. Mean frequency (days $\mathrm{yr}^{-1}$ ) of EH days during JulyAugust over a 38-yr time period for all observational stations in South Korea and Japan (except the islands south of $30^{\circ} \mathrm{N}$ ). The horizontal dashed line denotes $39^{\circ} \mathrm{N}$.

circulation patterns before $\mathrm{EH}$ occurrence and compared these patterns to derive typical precursory signals.

The objective of this study was to statistically determine the large-scale circulation anomalies responsible for the EH in South Korea and southern-central Japan. The organization of this paper is as follows. The data, definitions, and methods are described in section 2 . Section 3 compares the statistical properties of EH in South Korea and southern-central Japan. The large-scale circulation anomalies and physical processes related to $\mathrm{EH}$ are investigated in section 4 and the precursory circulation signals are explored in section 5. Section 6 summarizes our conclusions.

\section{Data and methodology}

\section{a. Data}

Daily maximum temperature $T_{\max }$ and precipitation data from 60 observational stations in South Korea and 100 observational stations in Japan were provided by the Korea Meteorological Administration (https://data.kma.go.kr/ data/grnd/selectAsosRltmList.do?pgmNo=36) and Japan Meteorological Agency (http://www.data.jma.go.jp/gmd/ risk/obsdl/index.php), respectively, over the 38 -yr period from 1979 to 2016. The observational stations were uniformly distributed over South Korea and Japan (Fig. 1). The datasets were quality controlled, removing the inhomogeneities caused by the changes not related to climate, such as the changes in observing locations, instrumentation, measurement techniques, or the observational environment (Park and Choi 2012; Chae et al. 2014).

Daily data from the National Centers for Environmental Prediction-Department of Energy (NCEP-DOE) Reanalysis-2 dataset (Kanamitsu et al. 2002) were used to 
document the associated circulation anomalies and physical processes. These data also span the time period 19792016, including multilevel variables of horizontal wind, air temperature, geopotential height, relative humidity, and vertical velocity with a horizontal resolution of $2.5^{\circ} \times 2.5^{\circ}$, and single-layer variables of the 2-m maximum temperature, total cloud cover, and surface flux data on a T62 Gaussian grid.

\section{b. Definitions}

We focused on the most frequent occurrences of $\mathrm{EH}$ during July-August in South Korea (60 stations) and southern-central Japan (78 stations) (Figs. 1 and 2). An EH day is defined as a day on which $T_{\max }>33^{\circ} \mathrm{C}$ at more than one-third of the stations (20 stations for South Korea and 26 stations for southern-central Japan). Our definition of EH is based on a unified threshold, that is, $33^{\circ} \mathrm{C}$, for both South Korea and southern-central Japan, because the percentiles of daily $T_{\max }$ during July-August are close over these regions. The 90th percentiles correspond to $32.6^{\circ}$ and $33^{\circ} \mathrm{C}$ over South Korea and southern-central Japan, respectively, and the 95 th percentiles are $33.4^{\circ}$ and $33.5^{\circ} \mathrm{C}$, respectively. In addition, the threshold of $33^{\circ} \mathrm{C}$ is adopted by the Korea Meteorological Administration to officially define $\mathrm{EH}$ and has been widely used in previous studies (e.g., Lee and Lee 2016; Yeh et al. 2018). This threshold has also an important meaning in human health-heat-related mortality rises remarkably once the temperature exceeds $33^{\circ} \mathrm{C}$ (Kyselý and Kim 2009). The requirement of exceeding one-third of the total stations is to emphasize the large-scale characteristics of circulation. We adjusted this criterion as exceeding half of the total stations and obtained similar results.

This definition yields a total of $395 \mathrm{EH}$ days in South Korea and 714 EH days in southern-central Japan. Among these days, there are 276 common $\mathrm{EH}$ days that appear simultaneously in both the areas. Composite analyses of circulation anomalies were performed on these common $\mathrm{EH}$ days to investigate the responsible physical processes (section 4). In addition to the simultaneous circulations, the precursory circulation anomalies before $\mathrm{EH}$ onset were also analyzed (section 5). Thus, we defined EH events as continuous common EH days or with only a 1-day break, and we obtained $41 \mathrm{EH}$ events. Furthermore, we excluded six events that occur within 5 days after the end of preceding EH events to eliminate the interferences (we showed in this paper the composite circulation anomalies from 5 days prior to $\mathrm{EH}$ onsets) and examined the residual 35 events.

\section{Statistical properties of EH in South Korea and Japan}

Figure 1 shows the 38-yr mean occurrence frequency of EH for each observational station in South Korea and (a) South Korea

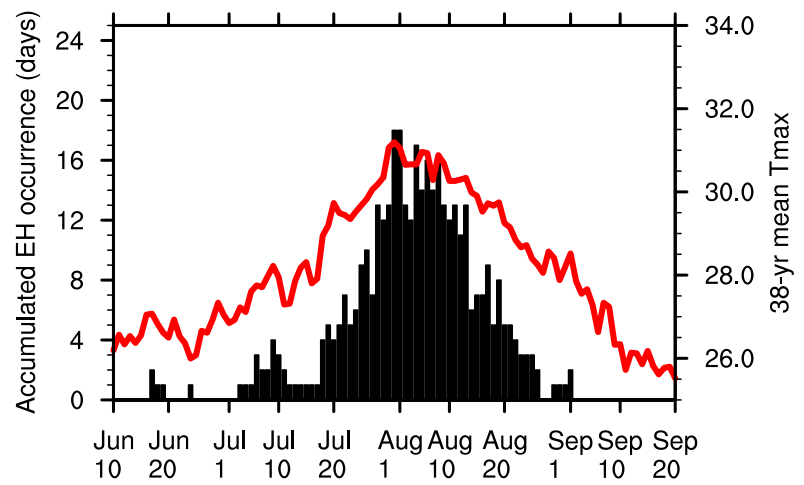

(b) southern-central Japan
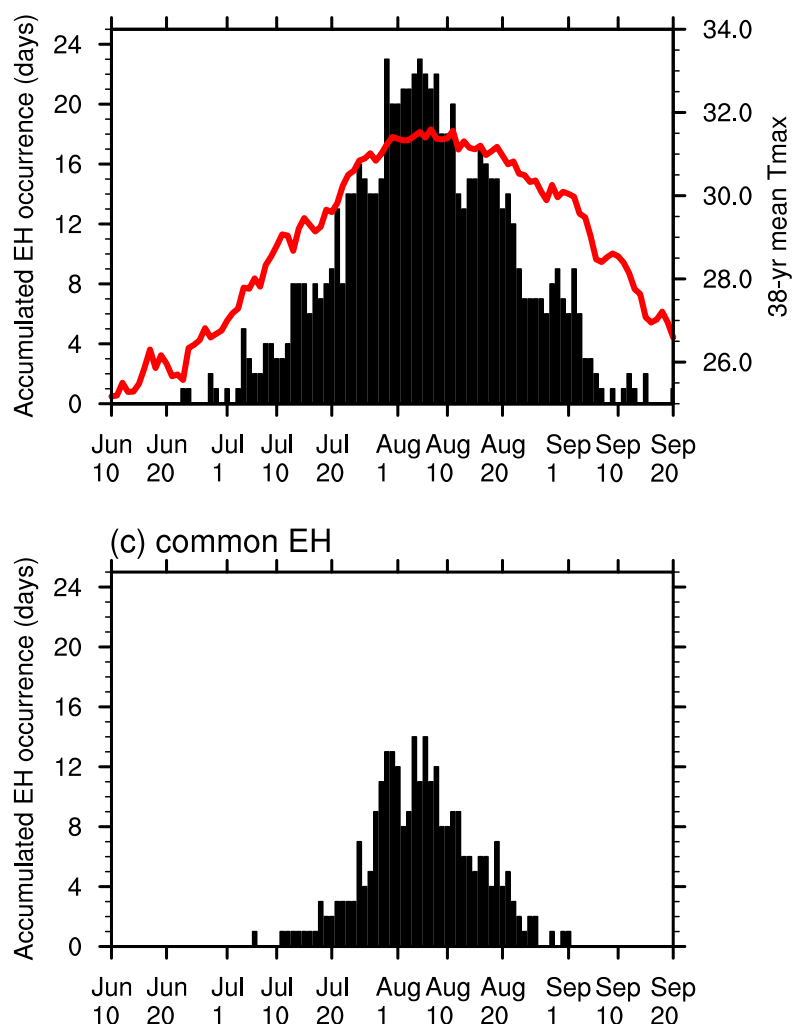

FIG. 2. Frequency of accumulated occurrence of EH (bars; left $y$ axis; days) in (a) South Korea, (b) southern-central Japan, and (c) common EH days from mid-June to late September for the time period 1979-2016. The red lines in (a) and (b) represent the climatological-mean $T_{\max }$ averaged over all stations (right $y$ axis; ${ }^{\circ} \mathrm{C}$ ).

Japan during July-August. The high frequency of EH occurs in inland South Korea, with the maximum value appearing in the southeastern region. For Japan, the frequency is high in the southern and central regions, but is low north of $39^{\circ} \mathrm{N}$, where the occurrence of $\mathrm{EH}$ is $<7$ days $\mathrm{yr}^{-1}$ for all stations. These patterns of the occurrence of EH in South Korea and Japan are consistent with those reported in previous studies (Murata 
et al. 2012; Lee and Lee 2016). This study mainly focuses on South Korea and southern-central Japan, where $\mathrm{EH}$ days frequently occur. The frequency of $\mathrm{EH}$ in southern-central Japan is higher than in South Korea because the unified threshold of $33^{\circ} \mathrm{C}$ for defining an $\mathrm{EH}$ corresponds to a slightly lower percentile of daily $T_{\max }$ during July-August in southern-central Japan than in South Korea (90th versus 92th percentiles).

The seasonal evolution of EH in South Korea and southern-central Japan show similar features (Fig. 2). The occurrence of EH in these two regions is concentrated in the period from late July to mid-August (20 July-20 August), during which the frequency accounts for $85 \%$ (South Korea) and $71 \%$ (southerncentral Japan) of the corresponding annual total amount (Figs. 2a,b). From mid-June to mid-July, when monsoon rainfall dominates South Korea and southern-central Japan (Kawamura and Murakami 1998; Byun and Lee 2002; Ding and Chan 2005; Choi et al. 2012), the climatological mean of $T_{\max }$ is $<30^{\circ} \mathrm{C}$ and only a few $\mathrm{EH}$ days are seen. As the rainy season ends, the occurrence of $\mathrm{EH}$ increases remarkably in late July and reaches an annual peak in early August, when the climatological mean of $T_{\max }$ reaches its highest values of $\sim 31^{\circ} \mathrm{C}$ in South Korea and $\sim 31.5^{\circ} \mathrm{C}$ in southern-central Japan. The occurrence of $\mathrm{EH}$ and the climatological $T_{\max }$ begin to decrease from mid-August. In September, almost no EH occurs in South Korea and very few occur in southerncentral Japan. The common EH days (Fig. 2c) show similar features of seasonal variation to those in Figs. 2a and $2 \mathrm{~b}$ and all occur in July and August.

Figure 3a shows the spatial distribution of the reanalysis 2-m air temperature (T2m) anomalies composited on the EH days in South Korea. The largest positive anomalies appear over the Korean Peninsula with a center $>1.5^{\circ} \mathrm{C}$. Concurrently, positive anomalies $\left(>0.6^{\circ} \mathrm{C}\right)$ are also found over eastern China and Japan, forming a band with a southwest-northeast tilt. The large domain of the positive anomalies suggests that the $\mathrm{EH}$ in South Korea is not merely local phenomena. Similarly, for the EH days in southern-central Japan (Fig. 3b), there is also a band structure of positive anomalies with a maximum center over central Japan. Positive anomalies of $>0.6^{\circ} \mathrm{C}$ can be observed over South Korea. Further examinations confirm that the majority of EH days in South Korea $(86 \%$, or 338 out of 395 days) and southern-central Japan ( $72 \%$, or 511 out of 714 days) are accompanied by an increase in temperature in the other location. These results indicate that the EH days in these two regions tend to appear simultaneously. The pattern of $\mathrm{T} 2 \mathrm{~m}$ anomalies for the common EH days (Fig. 3c) resembles that in Fig. 3a because the common $\mathrm{EH}$ days account for about $75 \%$
(295 out of 395 days) of the total number of EH days in South Korea. The results derived from the observational station data of $T_{\max }$ are given in Figs. 3d-f, which show consistent features with those in Figs. 3a-c, except that the amplitudes of the $T_{\max }$ anomalies are larger than those of the reanalysis $\mathrm{T} 2 \mathrm{~m}$ anomalies.

In a more general situation, Fig. 4 shows the scatterplot of $T_{\max }$ anomalies averaged over South Korea and southern-central Japan on each day during July-August for the time period 1979-2016. The daily $T_{\max }$ anomalies over these two regions are positively correlated with a correlation coefficient of 0.51 , which is significant at the $99 \%$ confidence level. Specifically, on about two-thirds of the total days, the signs of the $T_{\max }$ anomalies in these two regions are coherent (37\% in the first quadrant and $30 \%$ in the third quadrant). By contrast, on the other one-third of the total days, the signs of the $T_{\max }$ anomalies are opposite (16\% in the second quadrant and $17 \%$ in the fourth quadrant) and on these days the magnitudes of the $T_{\max }$ anomalies are smaller than those in the other two quadrants. This positive correlation of $T_{\max }$ anomalies supports the simultaneous occurrence of $\mathrm{EH}$ days in South Korea and southern-central Japan and implies that the temperature in these two regions may be influenced by the same large-scale atmospheric processes. Therefore EH days in South Korea and southern-central Japan can be combined to investigate the related mechanisms.

\section{Large-scale circulation anomalies on common EH days}

The circulation anomalies on common EH days are dominantly featured by an anomalous anticyclone throughout the troposphere over East Asia (Fig. 5). This anomalous anticyclone is strongest in the upper troposphere (Fig. 5a), where it occupies a large domain, spanning more than $40^{\circ}$ of longitude $\left(110^{\circ}-150^{\circ} \mathrm{E}\right)$ and more than $20^{\circ}$ of latitude $\left(30^{\circ}-52.5^{\circ} \mathrm{N}\right)$. This anomalous anticyclone shifts southward in the middle troposphere (Fig. 5b), with its center appearing over the Korean Peninsula, and covers a smaller horizontal scale than the anticyclone in the upper troposphere. The anomalous anticyclone is contracted further in the lower troposphere (Fig. 5c). Two anomalous cyclones are observed to the south and north of this anomalous anticyclone, respectively, but both of them show weak intensities.

The crucial factors that may influence air temperature are diagnosed by combining the large-scale circulation anomalies (Fig. 6). Significant subsidence anomalies associated with the deep anticyclonic anomaly over East Asia are observed (Fig. 6a), corresponding to the region of large positive $T_{\max }$ anomalies (Fig. 3c). This indicates 
(a) South Korea

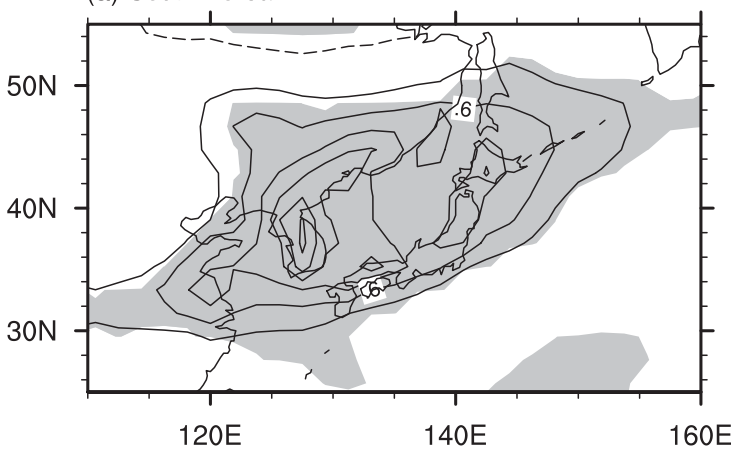

(b) southern-central Japan

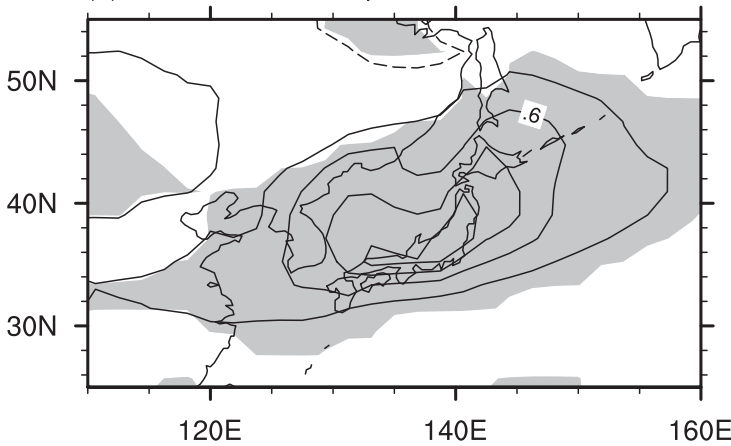

(c) common

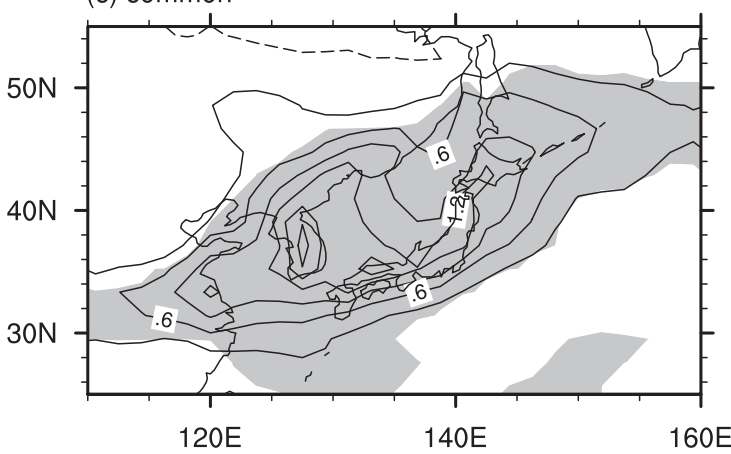

(d) South Korea

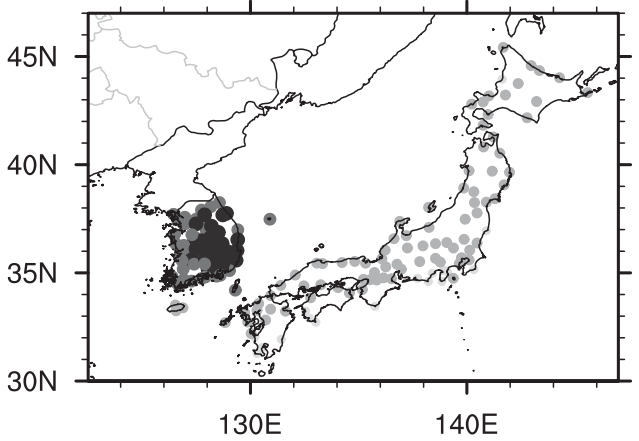

(e) southern-central Japan

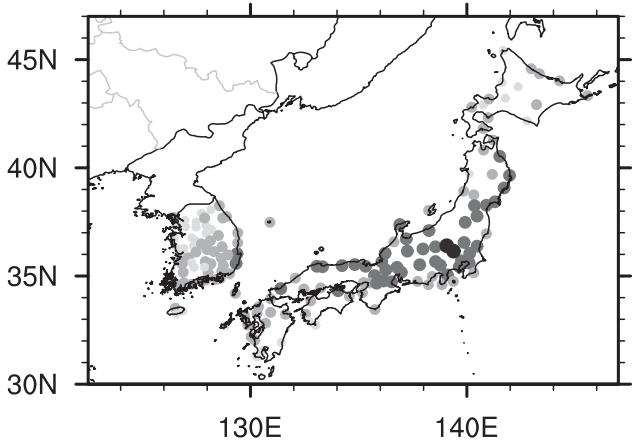

(f) common

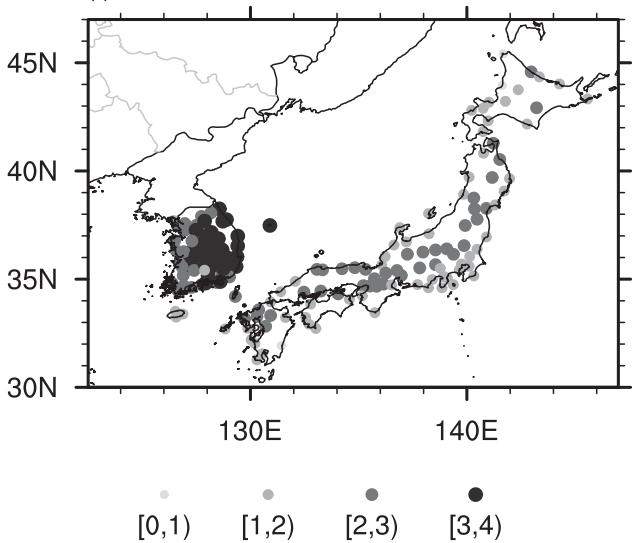

FIG. 3. Composite anomalies of reanalysis-based 2-m air temperature on EH days in (a) South Korea and (b) southern-central Japan during July-August. (c) As in (a) and (b), but for the common EH days. Gray shading indicates the $99 \%$ confidence level based on a Student's $t$ test. The contour interval is $0.3^{\circ} \mathrm{C}$, and the zero contours are omitted. (d)-(f) As in (a)-(c), respectively, but for the anomalies of observational $T_{\max }$.

that the significant subsidence anomaly, which causes enhanced adiabatic heating, greatly contributes to the anomalous atmospheric warming on EH days. The composite circulation, rather than the anomalies, on $\mathrm{EH}$ days indicate that the North Pacific subtropical high is located to the north of its climatological position, with an enhanced ridge extending from the East China Sea to southern-central Japan (not shown). The subsidence anomaly remarkably suppresses precipitation, which favors the occurrence of high temperatures. The areamean precipitation is 4.9 (2.0) $\mathrm{mm} \mathrm{day}^{-1}$ over South
Korea (southern-central Japan) on EH days, which is much lower than the climatological July-August mean of 11.9 (6.3) $\mathrm{mm} \mathrm{day}^{-1}$. Flux analysis suggests that the anomalous subsidence can considerably reduce cloud cover and thus increase the downward shortwave radiation flux, which contributes to higher temperatures through the enhanced upward sensible heat flux (not shown). By contrast, the anomalies in the longwave radiation flux and latent heat flux are weak on EH days.

In addition to vertical motion, horizontal temperature advection is also important in temperature change. 


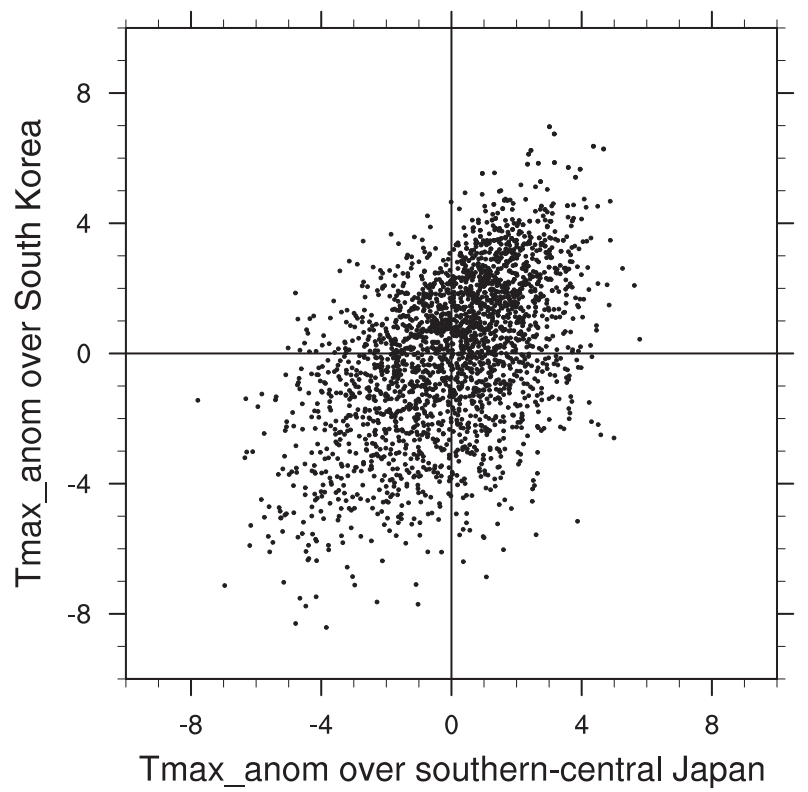

FIG. 4. Scatterplot of $T_{\max }$ anomalies $\left({ }^{\circ} \mathrm{C}\right)$ averaged over South Korea and southern-central Japan on each day during July-August for the time period 1979-2016.

However, the composite anomalies are insignificant and even negative (cold advection), over South Korea and southern-central Japan (Fig. 6b). A reduction in the water vapor content, which always accompanies the occurrence of EH in the Yangtze River valley and South China, has been suggested to favor an increase in temperature during the daytime by increasing the amount of downward shortwave radiation (Chen and Lu 2014a,b, 2015). Nevertheless, weak anomalies in the specific humidity at lower levels are observed (Fig. 6c), indicating a negligible role for water vapor in causing the $\mathrm{EH}$ days in South Korea and southern-central Japan, and confirming that the increased downward shortwave radiation on EH days is mainly induced by the anomalous subsidence. A belt of higher specific humidity extends from North China to northern Japan and can be attributed to the anomalous anticyclone (Fig. 5c), which enhances the northward transport of water vapor. To summarize, the significant subsidence anomaly related to the deep anomalous anticyclone is the dominant factor responsible for the occurrence of EH days in South Korea and southern-central Japan.

We can further confirm the important role of an anomalous anticyclone in inducing $\mathrm{EH}$ by verifying whether EH has a higher probability of occurrence when an anomalous anticyclone occurs over northeast Asia. The original probability of EH occurrence is $11.7 \%$, that is, 276 common EH days out of total 2356 days. This ratio increases to $19.5 \%, 1.7$ times higher than the original probability under the circumstance of anomalous anticyclone.

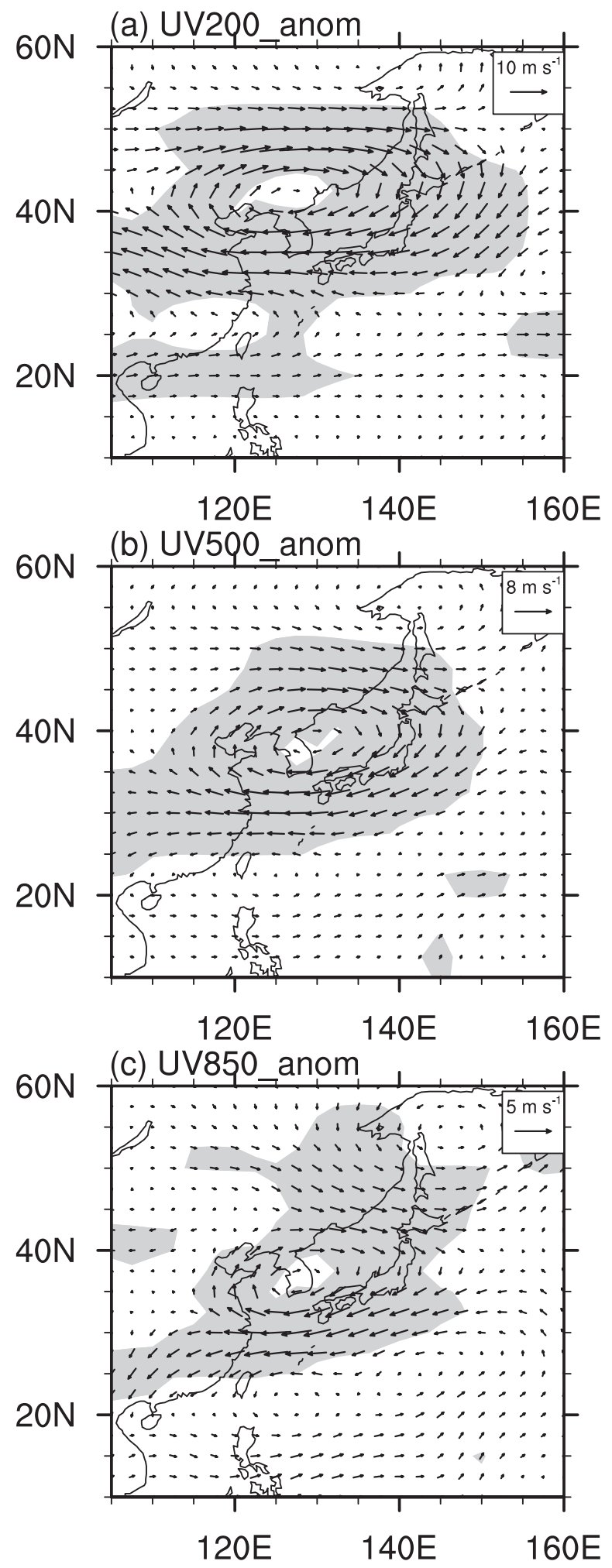

FIG. 5. Composite wind anomalies $\left(\mathrm{m} \mathrm{s}^{-1}\right)$ at (a) 200, (b) 500, and (c) $850 \mathrm{hPa}$ on the common $\mathrm{EH}$ days. Shading indicates the $95 \%$ confidence level based on a Student's $t$ test. 


\section{(a) omega $500 \mathrm{hPa}$}

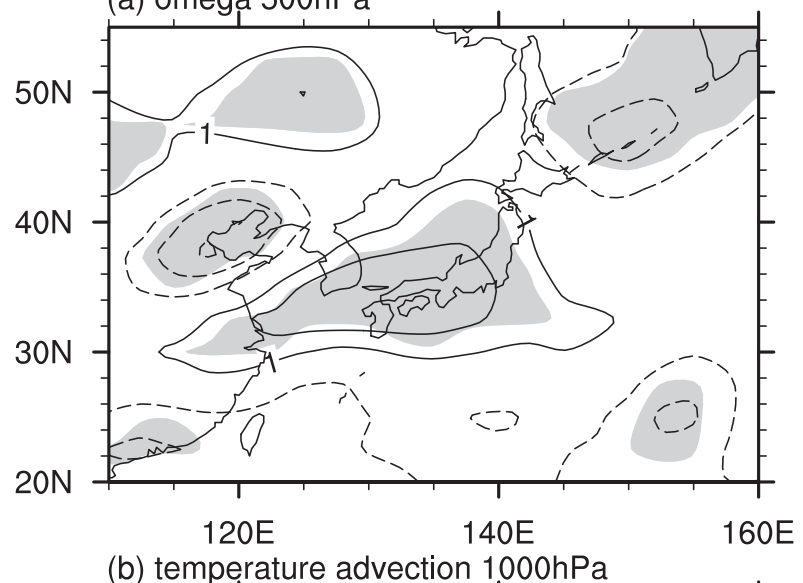

(b) temperature advection $1000 \mathrm{hPa}$

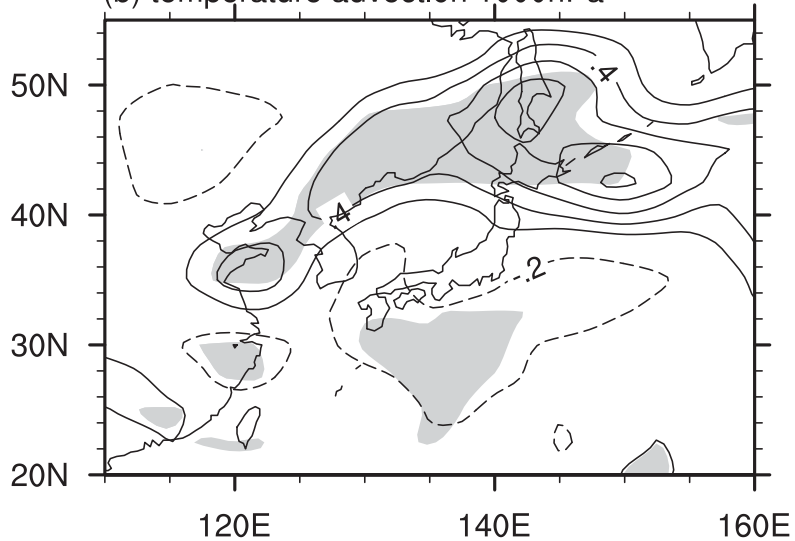

(c) specific humidity $850 \mathrm{hPa}$

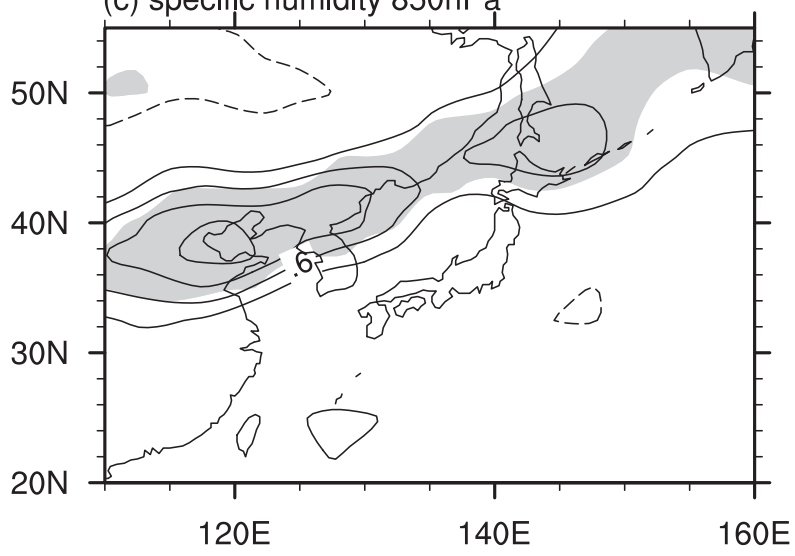

FIG. 6. Composite anomalies on the common EH days: (a) 500-hPa vertical pressure velocity (contours; interval is $1 \times$ $10^{-2} \mathrm{~Pa} \mathrm{~s}^{-1}$ ), (b) $1000-\mathrm{hPa}$ horizontal advection of temperature (contours; interval is $0.2 \times 10^{-5} \mathrm{~K} \mathrm{~s}^{-1}$ ), and (c) 850 - $\mathrm{hPa}$ specific humidity (contours; interval is $0.3 \mathrm{~g} \mathrm{~kg}^{-1}$ ). The zero contours are omitted. Shading indicates the $95 \%$ confidence level based on a Student's $t$ test.

Here, we define an anomalous anticyclone index as the $200-\mathrm{hPa}$ vorticity anomaly averaged over $35^{\circ}-47.5^{\circ} \mathrm{N}$, $115^{\circ}-145^{\circ} \mathrm{E}$ based on the results in Fig. 5. Under the circumstance of the anticyclonic anomaly lower than -1 standard deviation, the ratio of EH occurrence increases to $28.4 \%$, more than twice the original probability. These results indicate that $\mathrm{EH}$ has a higher occurrence chance under anticyclonic anomaly, which agrees with the results of the composite circulation anomalies.

\section{Precursory circulation anomalies}

The evolution of circulation anomalies before the occurrence of $\mathrm{EH}$ events was investigated to obtain valuable precursory signals. The 276 common EH days are divided into $35 \mathrm{EH}$ events (see section 2) and the first day of each event is designated as the onset day (day 0 ). Composite anomalies are constructed with respect to this day. The negative and positive days represent the days before and after the onset day, respectively.

Figure 7 shows the composite upper-level circulation anomalies before day 0 . An anomalous anticyclone appears to the east of the Aral Sea on days -5 and -4 (Fig. 7a). This anticyclone intensifies on days -3 and -2 , when a downstream anticyclone forms over East Asia and a weak cyclonic anomaly appears to the south between the two anticyclones. These circulation anomalies form a wave structure along $40^{\circ} \mathrm{N}$, which can be clearly seen by the alternating appearance of the meridional wind anomalies, despite the reason for the more southern location of the cyclonic anomaly being unclear. The anomalous anticyclone over East Asia is remarkably enhanced on days -1 and 0 (Fig. 7c) and induces the onset of an $\mathrm{EH}$ event, while the upstream circulation anomalies disappear. This evolution of circulation anomalies suggests that the formation and enhancement of the anomalous anticyclone over East Asia is associated with the propagation of a Rossby wave packet initiated in the upstream region and featured by a clear eastward dispersion of energy. By contrast, the evolution of circulation anomalies in the lower troposphere features the local development of an anomalous anticyclone over East Asia (not shown), concurrent with the enhancement of the anticyclonic anomaly in the upper troposphere. No significant anomaly of circulation or convection appear over the tropical western North Pacific before the onset of the EH event (not shown), which indicates that, on the synoptic scale, the formation of the anomalous anticyclone over East Asia is not necessarily related to tropical convection. This is distinct from the important influence of tropical forcing on forming the summer-mean anticyclonic anomaly over East Asia, which greatly modulates the interannual variation of the frequency of heat waves in South Korea (Lee and Lee 2016).

Two indices are defined to evaluate the relationship between the upstream and local circulation anomalies 

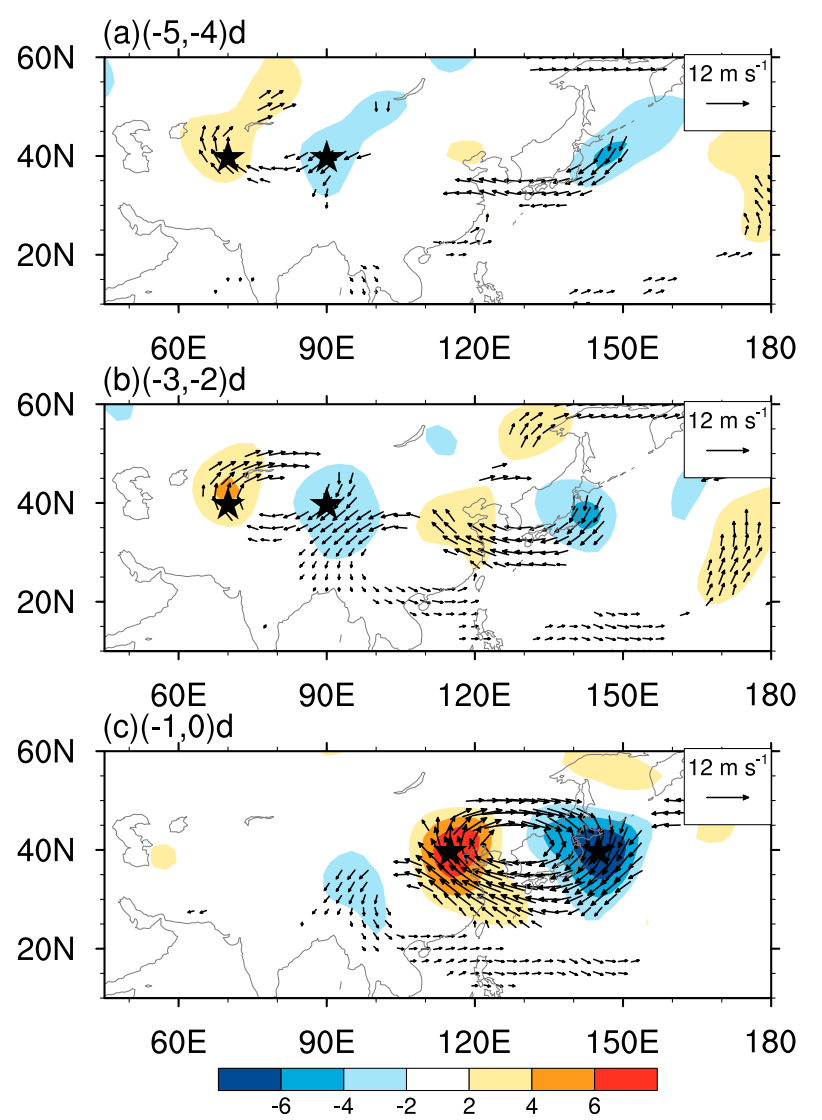

FIG. 7. Composite evolution of 200-hPa wind anomalies (vectors; $\mathrm{m} \mathrm{s}^{-1}$ ) and meridional $v$-wind components (colors; $\mathrm{ms}^{-1}$ ) on (a) days -5 and -4 , (b) days -3 and -2 , and (c) days -1 and 0 . Only the significant wind anomalies (vectors), with either the zonal or the meridional component reaching the $90 \%$ confidence level, are shown. Stars denote the positions of the large $v$-wind anomalies used to define the two indices in Fig. 8.

case by case. The central Asian index is defined as the difference in the meridional wind anomalies between $40^{\circ} \mathrm{N}, 70^{\circ} \mathrm{E}$ and $40^{\circ} \mathrm{N}, 90^{\circ} \mathrm{E}$ averaged from days -5 to -2 , which examines the preceding upstream circulation anomalies. Likewise, the East Asian index is defined as the difference in the meridional wind anomalies between $40^{\circ} \mathrm{N}, 115^{\circ} \mathrm{E}$ and $40^{\circ} \mathrm{N}, 145^{\circ} \mathrm{E}$ averaged during days -1 and 0 and examines the local circulation anomalies at the onset time. The positive indices indicate anticyclonic anomalies, which is consistent with the results of the composite analysis (Fig. 7).

Figure 8 shows the scatterplot of the two indices. The East Asian index is positive in 29 of the total 35 events, confirming that most of onsets of EH events are associated with anticyclonic anomalies over East Asia. The onsets of EH events for the residual six events with a negative index are also related to anticyclonic anomalies, but the positions of the anticyclones show some discrepancies with the composite analysis in Fig. 7c.

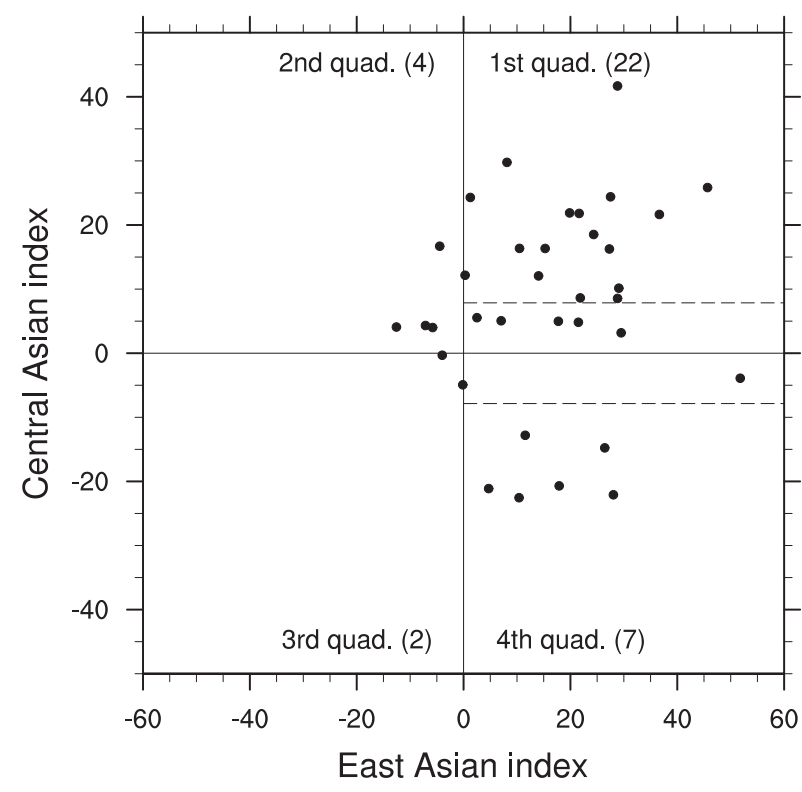

FIG. 8. Scatterplot of central Asian anticyclone index and East Asian anticyclone index for the $35 \mathrm{EH}$ events (see text for details of definitions). The dashed lines in the first and fourth quadrants indicate \pm 0.5 standard deviations of the central Asian index.

Among the 29 events with a positive East Asian index, the central Asian index is positive in 22 events (first quadrant), indicating that the anticyclonic anomaly over East Asia is generally preceded by an upstream anticyclonic anomaly to the east of the Aral Sea, consistent with the composite results (Fig. 7). However, the central Asian index is negative for the other seven events (fourth quadrant), implying that an upstream cyclonic anomaly precedes the anticyclonic anomaly over East Asia, which is distinctly different from the results of the composite analysis (Fig. 7). To show how both the contrasting upstream circulation anomalies can cause the anomalous anticyclone over East Asia, the 17 events in the first quadrant and the 6 events in the fourth quadrant are composited. The events are selected according to the criterion of the central Asian index exceeding 0.5 standard deviations or $7.86 \mathrm{~m} \mathrm{~s}^{-1}$.

Figure 9 shows the composite evolution of circulation anomalies for these events. For the 17 events, the circulation anomalies related to the onset of $\mathrm{EH}$ events can be tracked back to days -7 and -6 , when a wave train forms spanning southeastward from the North Atlantic Ocean to the Eurasian continent (Fig. 9a). The wave train then propagates eastward across the Eurasian continent along the Asian westerly jet because of the eastward dispersion of energy, featured by the successive downstream development of new circulation centers while vanishing of the upstream centers (Figs. 9b-d). A downstream anticyclonic anomaly appears to the 
1st quadrant (17 events)

(a) $(-7,-6) d$

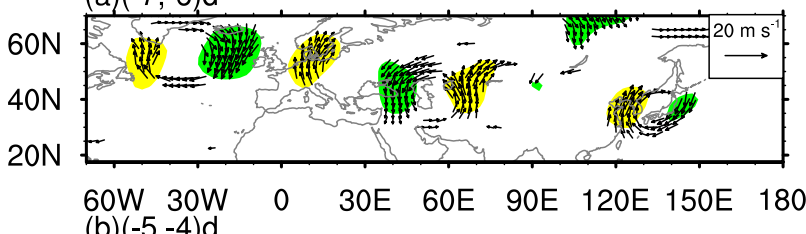

(b) $(-5,-4) d$
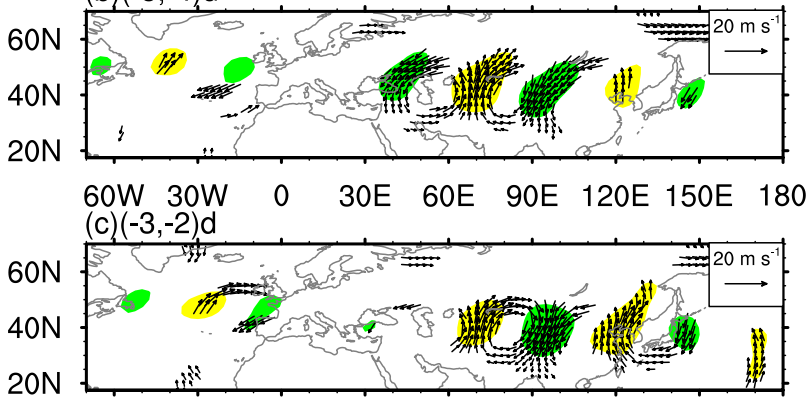

60W 30W $0 \quad 30 \mathrm{E} \quad 60 \mathrm{E} \quad 90 \mathrm{E}$ 120E $150 \mathrm{E} \quad 180$ (d) $(-1,0) d$

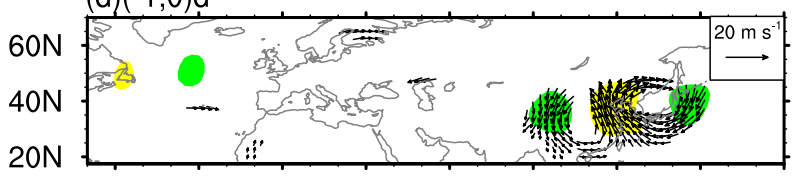

60W 30W $0 \quad 30 \mathrm{E} \quad 60 \mathrm{E} \quad 90 \mathrm{E} \quad 120 \mathrm{E}$ 150E 180 4th quadrant (6 events)
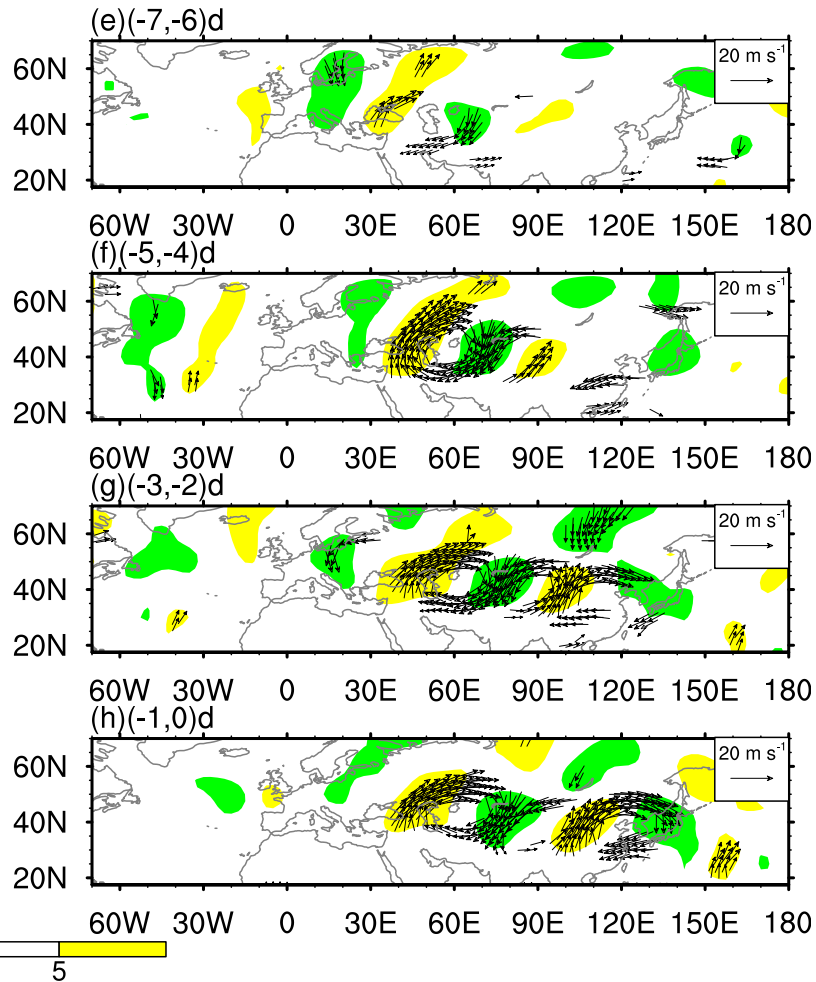

FIG. 9. Composite evolution of 200-hPa wind anomalies (vectors; $\mathrm{m} \mathrm{s}^{-1}$ ) and the meridional $v$-wind components (colors; $\mathrm{m} \mathrm{s}^{-1}$ ) before the onset day (day 0). (a)-(d) The 17 events in the first quadrant of Fig. 8 and (e)-(h) the 6 events in the fourth quadrant of Fig. 8 . Only the significant wind anomalies (vectors), with either the zonal or the meridional component reaching the $95 \%$ confidence level, are shown.

east of the Aral Sea $\left(70^{\circ}-90^{\circ} \mathrm{E}\right)$ on days -5 and -4 (Fig. 9b), which is the key circulation center discerned and discussed in Fig. 7a. The subsequent evolution of the circulation centers are consistent with those shown in Figs. $7 \mathrm{~b}$ and $7 \mathrm{c}$. This wave pattern, which features quasi-stationary phases and the eastward dispersion of energy along the Asian westerly jet, resembles the previously described Silk Road pattern (e.g., Lu et al. 2002; Enomoto et al. 2003; Ding and Wang 2005).

The composite evolution of circulation anomalies for the six events show notable differences in their spatial patterns (Figs. 9e-h). We examined the evolution of circulation for each of the six events and found that they have a high case-to-case coherence. Specifically, an anomalous cyclone and anticyclone emerge over eastern Europe and the Caspian Sea on days -7 and -6 (Fig. 9e), respectively. The anomalous anticyclone enhances on days -5 and -4 (Fig. 9f) and a new cyclone is generated to the east $\left(70^{\circ}-90^{\circ} \mathrm{E}\right)$. This wave pattern is clearly out of phase with that for the 17 events in the first quadrant (Fig. 9b). An anomalous anticyclone then forms over East Asia on days -3 and -2 (Fig. 9g), which further intensifies on days -1 and 0 (Fig. 9h). This anticyclonic anomaly is located slightly to the west of the anticyclone in Fig. 9d. From a large-scale view, from the Caspian Sea to the East Asian coast, the wave trains display a striking quadrupole structure for the 17 events in the first quadrant, but a tripole structure for the six events in the fourth quadrant, implying that they have different wavelengths.

To better illustrate the evolution of the circulation anomalies along midlatitudes, Fig. 10 shows the longitudetime sections of the 200-hPa meridional $v$-wind anomalies averaged over $37.5^{\circ}-42.5^{\circ} \mathrm{N}$. For the 17 events in the first quadrant (Fig. 10a), the eastward movement of the maximum amplitude clearly indicates the eastward dispersion of energy by the wave train, with an estimated group velocity of $18.3 \mathrm{~m} \mathrm{~s}^{-1}$. By contrast, the phases of the wave train remain almost stationary. The wave structure shows a zonal wavenumber of 7 , consistent with the Rossby wave along the Asian westerly jet during the boreal summer identified by Ambrizzi et al. (1995). The wave pattern for the EH event in 2004 (Enomoto et al. 2009) belongs to this type, although the pattern for a single year is less structured than in the results of the composite analysis.

The composite evolution of the $v$-wind anomalies for the six events in the fourth quadrant (Fig. 10b) also shows an eastward dispersion of energy, with a group velocity similar to that of the 17 events in the first 
(a) 1st quadrant (17 events)

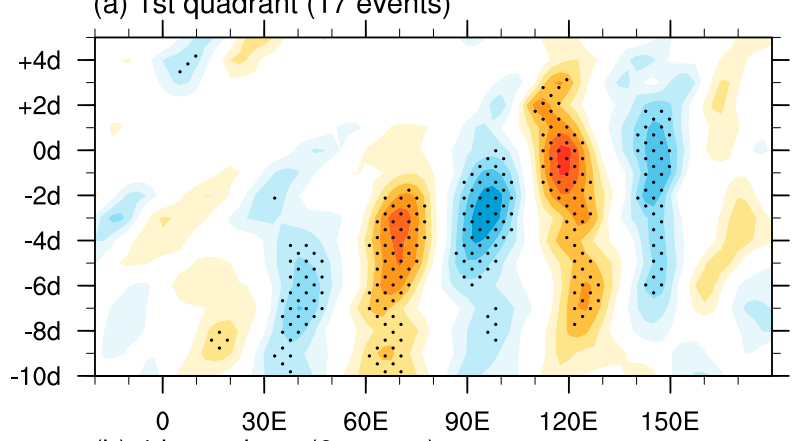

(b) 4th quadrant ( 6 events)

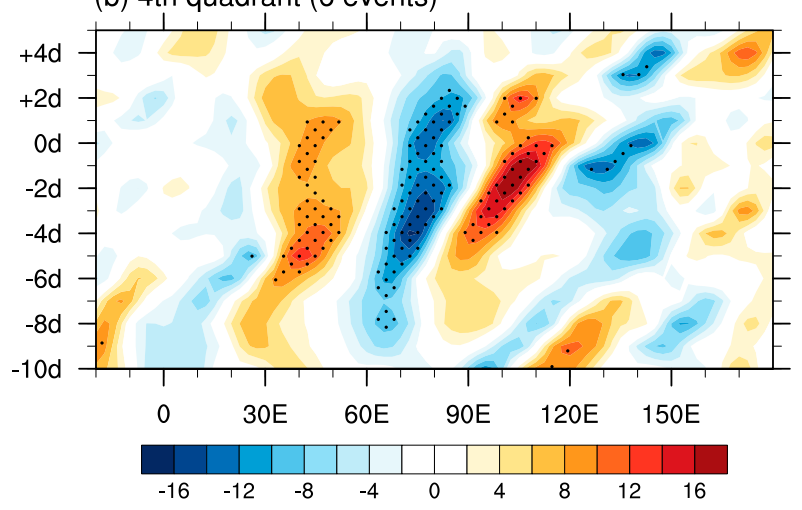

FIG. 10. Longitude-time section of the $200-\mathrm{hPa}$ meridional $v$-wind anomalies averaged between $37.5^{\circ}$ and $42.5^{\circ} \mathrm{N}$ around the onset day of EH events (day 0). (a) The 17 events in the first quadrant of Fig. 8 and (b) the 6 events in the fourth quadrant of Fig. 8. Stippled regions indicate the $95 \%$ confidence level based on a Student's $t$ test. Negative and positive days represent the days before and after the onset day, respectively.

quadrant. However, striking differences are found in the horizontal scale of the wave pattern. Specifically, the wavelength is longer for these six events, indicated by a smaller zonal wavenumber of about 6 , which is consistent with Fig. 9. In association with this difference in wavelength, the wave patterns over the upstream region $\left(30^{\circ}-100^{\circ} \mathrm{E}\right)$, which are related to the anticyclonic anomaly over East Asia, are almost out of phase for the two kinds of event. However, despite these differences in the precursory circulation anomalies, no remarkable discrepancy is found in the EH occurrence time, persistence or intensity between these two types of event (not shown).

The difference in zonal wavelength or wavenumber is therefore crucial in the distinct upstream circulation anomalies - that is, the anticyclonic anomaly for the 17 events in the first quadrant, but the cyclonic anomaly for the six events in the fourth quadrant over central Asia. The Rossby wavenumber with a zero-phase velocity (Ks) can be theoretically determined by the intensity and horizontal distribution of the background zonal wind. To be more specific, $\mathrm{Ks}=\sqrt{\beta^{*} / U}$, where $\beta^{*}=\beta-\partial^{2} U / \partial y^{2}$, namely, the poleward gradient of absolute vorticity (Hoskins and Ambrizzi 1993). Figures 11a and 11b show the spatial distribution of Ks for the two types of event. Here, the 200-hPa zonal winds averaged from days -10 to +4 , the period covering the clear wave propagation (Fig. 10), are used as the basic flow $U$. For both types of event, the Ks maxima show a zonally elongated band from west Asia to East Asia, where the Asian westerly jet is located, demonstrating that the jet streams in these events can constrain the propagation of the Rossby wave (Hoskins and Ambrizzi 1993). The values of Ks are ignored in the tropics where the easterlies appear. Specifically, Ks is 7-8 along the westerly jet for the 17 events in the first quadrant (Fig. 11a), but is smaller for the six events in the fourth quadrant, especially in the upstream region of west-central Asia $\left(40^{\circ}-90^{\circ} \mathrm{E}\right)$, where Ks is 6-7 (Fig. 11b). These theoretically determined wavenumbers broadly agree with those of the observed waves for the two types of event (Figs. 9 and 10).

Ks is dependent on both the intensity and shape of the Asian westerly jet. A narrower jet, indicating a smaller $\partial^{2} U / \partial y^{2}$, and a weaker jet induce a greater Ks, according to the formula. The composite Asian jet for the 17 events in the first quadrant does tend to be narrower, indicated by a smaller meridional range of zonal wind $>20 \mathrm{~m} \mathrm{~s}^{-1}$, and weaker than the composite Asian jet for the six events in the fourth quadrant (Fig. 11c). This suggests that the Asian westerly jet, as the basic flow, can determine not only the propagation, but also the horizontal structure of the Rossby wave in terms of spatial scale and geographical distribution.

We further examined the probability of $\mathrm{EH}$ occurrence when the two distinct wave patterns show up. The method of selecting wave-pattern events is as follows. For each day during July-August, we calculated the central Asian index averaged from day -5 to day -2 , and the East Asian index averaged from day -1 to day 0 as mentioned before, then designated type-1 (type-2) wave patterns if the central Asian index is above +1 (below -1) standard deviation and the East Asian index is above +1 standard deviation. Accordingly, we obtained 123 type- 1 patterns and 35 type- 2 patterns. It was found that the probability of $\mathrm{EH}$ occurrence within following 3 days is $41 \%$ and $46 \%$ for the type- 1 and type2 patterns, respectively, both much higher than the original probability $(11.7 \%)$, suggesting that the two types of wave pattern are indicative to the occurrence of EH over South Korea and southern-central Japan.

\section{Conclusions and discussion}

Using observational data of the daily $T_{\max }$ provided by the Korea Meteorological Administration and the Japan Meteorological Agency, this study focused on the 
(a) Ks 1st quad. (17 events)

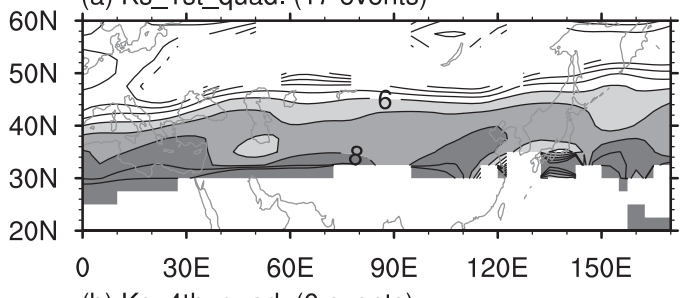

(b) Ks_4th_quad. (6 events)

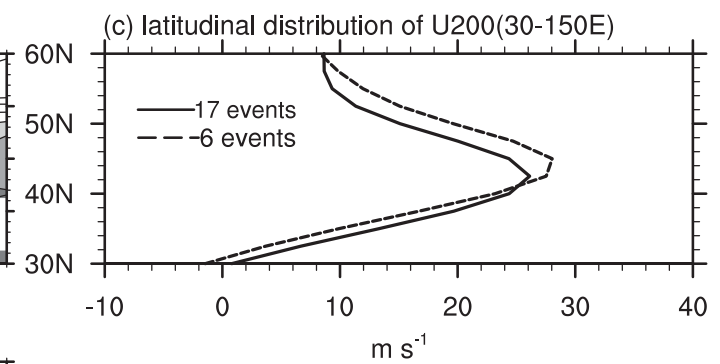

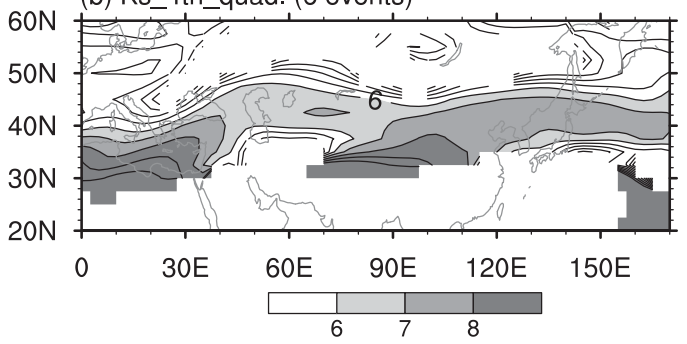

FIG. 11. Spatial distribution of Rossby wavenumber Ks (contour interval is 1) defined in Hoskins and Ambrizzi (1993) for (a) the 17 events in the first quadrant and (b) the 6 events in the fourth quadrant of Fig. 8. Shading represents values $>6$. (c) Latitudinal distributions of the $200-\mathrm{hPa}$ zonal wind velocities $\left(\mathrm{m} \mathrm{s}^{-1}\right)$ averaged over days -10 to +4 and $30^{\circ}-150^{\circ} \mathrm{E}$.

EH days in South Korea and southern-central Japan, which show similar features. The EH days in both regions are concentrated in the period from late July to midAugust and peak in early August. In addition, the EH in these two regions tends to appear simultaneously. The EH days in South Korea and southern-central Japan were therefore combined to further explore the related atmospheric circulation patterns and physical processes.

The common EH days in South Korea and southerncentral Japan are characterized by an anomalous anticyclone throughout the troposphere over East Asia. In association with this deep anomalous anticyclone, significantly subsidence anomalies are observed over South Korea and southern-central Japan. The anomalous subsidence intensifies adiabatic heating and increases the downward shortwave radiation flux, leading to anomalous atmospheric warming through an enhanced upward sensible heat flux. By contrast, horizontal temperature advection, the water vapor content, the longwave radiation flux and the latent heat flux make negligible contributions to the occurrence of $\mathrm{EH}$ days.

The 276 common EH days were divided into $35 \mathrm{EH}$ events (each event consisting of consecutive EH days) to explore the precursory signals. The first day of each event was designated as the onset day of the EH event. The results indicate that the onset of an EH event is caused by precursory wave trains originating upstream and featuring the eastward dispersion of energy along the Asian westerly jet in the upper troposphere. Two types of wave trains were identified, which can be clearly distinguished by anticyclonic or cyclonic anomalies over central Asia, both corresponding to subsequent anticyclonic anomalies over East Asia. The difference between the wave trains is caused by the difference in wavenumber, which can be attributed to the difference in the shape and intensity of the Asian westerly jet. A narrower and weaker Asian westerly jet results in a greater wavenumber for the type of anticyclonic anomalies over central Asia, relative to the type of cyclonic anomalies over central Asia. This demonstrates that the Asian westerly jet can modulate not only the propagation, but also the structure of Rossby waves.

The present results confirm that the characteristics of the EH-related circulation are dependent on regions. The warm advection by lower-level circulation anomalies, which is crucial for EH in North China (Chen and Lu 2015; Freychet et al. 2017), is not crucial for $\mathrm{EH}$ in South Korea and southern-central Japan. In addition, the EH-related anticyclonic anomalies are usually accompanied by anomalous low humidity in Mongolia and China (Chen and Lu 2016; Erdenebat and Sato 2016; Wang et al. 2016), but correspond to a negligible change of humidity in the study area (Fig. 6). Teleconnection patterns are responsible for $\mathrm{EH}$ in various regions, including Europe, North America, and China (e.g., Lyon and Dole 1995; Schubert et al. 2011; Teng et al. 2013; Chen et al. 2016; Gao et al. 2018). The two wave patterns identified in this study are different from these teleconnection patterns in terms of the wave path and structure, confirming regional dependence of EHrelated circulations.

Acknowledgments. We sincerely thank Dr. Shoji Kusunoki for providing the information on the observational 
station data in Japan, and greatly appreciate the comments from the three anonymous reviewers. This work was supported by the National Natural Science Foundation of China (Grants 41605027, 41721004, and 41730963).

\section{REFERENCES}

Ambrizzi, T., B. J. Hoskins, and H.-H. Hsu, 1995: Rossby wave propagation and teleconnection patterns in the austral winter. J. Atmos. Sci., 52, 3661-3672, https://doi.org/10.1175/ 1520-0469(1995)052<3661:RWPATP $>2.0$.CO;2.

Black, E., M. Blackburn, G. Harrison, B. Hoskins, and J. Methven, 2004: Factors contributing to the summer 2003 European heat wave. Weather, 59, 217-223, https://doi.org/ 10.1256/wea.74.04.

Boo, K.-O., W.-T. Kwon, and H.-J. Baek, 2006: Change of extreme events of temperature and precipitation over Korea using regional projection of future climate change. Geophys. Res. Lett., 33, L01701, https://doi.org/10.1029/2005GL023378.

Byun, H.-R., and D.-K. Lee, 2002: Defining three rainy seasons and the hydrological summer monsoon in Korea using available water resources index. J. Meteor. Soc. Japan, 80, 33-44, https:// doi.org/10.2151/jmsj.80.33.

Chae, J.-H., M.-S. Park, and Y.-J. Choi, 2014: The WISE quality control system for integrated meteorological sensor data (in Korean). Atmosphere, 24, 445-456, https://doi.org/10.14191/ Atmos.2014.24.3.445.

Chen, R., and R. Lu, 2014a: Large-scale circulation anomalies associated with 'tropical night' weather in Beijing, China. Int. J. Climatol., 34, 1980-1989, https://doi.org/10.1002/ joc.3815.

— Beijing: Atypical configurations between high temperature and humidity. Mon. Wea. Rev., 142, 1792-1802, https://doi.org/ 10.1175/MWR-D-13-00289.1.

$\longrightarrow$, and — 2015: Comparisons of the circulation anomalies associated with extreme heat in different regions of eastern China. J. Climate, 28, 5830-5844, https://doi.org/10.1175/ JCLI-D-14-00818.1.

— , and - 2016: Role of large-scale circulation and terrain in causing extreme heat in western north China. J. Climate, 29, 2511-2527, https://doi.org/10.1175/JCLI-D-15-0254.1.

—, Z. Wen, and R. Lu, 2016: Evolution of the circulation anomalies and the quasi-biweekly oscillations associated with extreme heat events in southern China. J. Climate, 29, 69096921, https://doi.org/10.1175/JCLI-D-16-0160.1.

Choi, G., and Coauthors, 2009: Changes in means and extreme events of temperature and precipitation in the Asia-Pacific Network region, 1955-2007. Int. J. Climatol., 29, 1906-1925, https://doi.org/10.1002/joc.1979.

Choi, K.-S., B. Wang, and D.-W. Kim, 2012: Changma onset definition in Korea using the available water resources index and its relation to the Antarctic oscillation. Climate Dyn., 38, 547562, https://doi.org/10.1007/s00382-010-0957-1.

Ding, Q., and B. Wang, 2005: Circumglobal teleconnection in the Northern Hemisphere summer. J. Climate, 18, 3483-3505, https://doi.org/10.1175/JCLI3473.1.

Ding, Y., and J. C. L. Chan, 2005: The East Asian summer monsoon: An overview. Meteor. Atmos. Phys., 89, 117-142, https:// doi.org/10.1007/s00703-005-0125-z.

Easterling, D. R., G. A. Meehl, C. Parmesan, S. A. Changnon, T. R. Karl, and L. O. Mearns, 2000: Climate extremes: observations, modeling, and impacts. Science, 289, 2068-2074, https://doi.org/ 10.1126/science.289.5487.2068.

Enomoto, T., B. J. Hoskins, and Y. Matsuda, 2003: The formation mechanism of the Bonin high in August. Quart. J. Roy. Meteor. Soc., 129, 157-178, https://doi.org/10.1256/qj.01.211.

—, H. Endo, Y. Harada, and W. Ohfuchi, 2009: Relationship between high-impact weather events in Japan and propagation of Rossby waves along the Asian jet in July 2004. J. Meteor. Soc. Japan, 87, 139-156, https://doi.org/10.2151/jmsj.87.139.

Erdenebat, E., and T. Sato, 2016: Recent increase in heat wave frequency around Mongolia: Role of atmospheric forcing and possible influence of soil moisture deficit. Atmos. Sci. Lett., 17, 135-140, https://doi.org/10.1002/asl.616.

Freychet, N., S. Tett, J. Wang, and G. Hegerl, 2017: Summer heat waves over Eastern China: Dynamical processes and trend attribution. Environ. Res. Lett., 12, 024015, https://doi.org/ 10.1088/1748-9326/aa5ba3.

Gao, M., J. Yang, B. Wang, S. Zhou, D. Gong, and S.-J. Kim, 2018: How are heat waves over Yangtze River valley associated with atmospheric quasi-biweekly oscillation? Climate Dyn., 51, 4421-4437, https://doi.org/10.1007/s00382-017-3526-z.

García-Herrera, R., J. Díaz, R. M. Trigo, and E. Hernández, 2005: Extreme summer temperatures in Iberia: Health impacts and associated synoptic conditions. Ann. Geophys., 23, 239-251, https://doi.org/10.5194/angeo-23-239-2005.

Griffiths, G. M., and Coauthors, 2005: Change in mean temperature as a predictor of extreme temperature change in the AsiaPacific region. Int. J. Climatol., 25, 1301-1330, https://doi.org/ 10.1002/joc.1194.

Hoskins, B. J., and T. Ambrizzi, 1993: Rossby wave propagation on a realistic longitudinally varying flow. J. Atmos. Sci., $\mathbf{5 0}$, 1661-1671, https://doi.org/10.1175/1520-0469(1993)050<1661: RWPOAR $>2.0 . C O ; 2$.

Imada, Y., H. Shiogama, M. Watanabe, M. Mori, M. Ishii, and M. Kimoto, 2014: The contribution of anthropogenic forcing to the Japanese heat waves of 2013 [in "Explaining Extreme Events of 2013 from a Climate Perspective"']. Bull. Amer. Meteor. Soc., 95 (9), S52-S54.

IPCC, 2013: Summary for policymakers. Climate Change 2013: The Physical Science Basis, T. F. Stocker et al., Eds., Cambridge University Press, 3-29.

Kanamitsu, M., W. Ebisuzaki, J. Woollen, S.-K. Yang, J. J. Hnilo, M. Fiorino, and G. L. Potter, 2002: NCEP-DOE AMIP-II Reanalysis (R-2). Bull. Amer. Meteor. Soc., 83, 1631-1643, https://doi.org/10.1175/BAMS-83-11-1631.

Kawamura, R., and T. Murakami, 1998: Baiu near Japan and its relation to summer monsoons over Southeast Asia and the western North Pacific. J. Meteor. Soc. Japan, 76, 619-639, https://doi.org/10.2151/jmsj1965.76.4_619.

Kim, E.-B., 2013: Evaluation of human-body effect and potential risk forecasting models by high temperature environment. Ph.D. thesis, Inje University, 230 pp.

_ - J.-K. Park, and W.-S. Jung, 2014: A study of the occurrence characteristics of tropical night day and extreme heat day in the metropolitan city, Korea (in Korean). J. Environ. Sci. Int., 23, 873-885, https://doi.org/10.5322/JESI.2014.5.873.

Kim, Y.-J., H. Kim, Y.-K. Kim, J.-K. Kim, and Y.-M. Kim, 2014: Evaluation of thermal environments during the heat waves of summer 2013 in Busan metropolitan area (in Korean). J. Environ. Sci. Int., 23, 1929-1941, https://doi.org/10.5322/ JESI.2014.23.11.1929.

Kyselý, J., and J. Kim, 2009: Mortality during heat waves in South Korea, 1991 to 2005: How exceptional was the 1994 heat 
wave? Climate Res., 38, 105-116, https://doi.org/10.3354/ cr00775.

Lau, W. K. M., and K.-M. Kim, 2012: The 2010 Pakistan flood and Russian heat wave: Teleconnection of hydrometeorological extremes. J. Hydrometeor., 13, 392-403, https://doi.org/ 10.1175/JHM-D-11-016.1.

Lee, J., 2017: Future trend in seasonal lengths and extreme temperature distributions over South Korea. Asia-Pac. J. Atmos. Sci., 53, 31-41, https://doi.org/10.1007/s13143-017-0002-y.

Lee, W.-S., and M.-I. Lee, 2016: Interannual variability of heat waves in South Korea and their connection with large-scale atmospheric circulation patterns. Int. J. Climatol., 36, 48154830, https://doi.org/10.1002/joc.4671.

Loikith, P. C., and A. J. Broccoli, 2012: Characteristics of observed atmospheric circulation patterns associated with temperature extremes over North America. J. Climate, 25, 7266-7281, https://doi.org/10.1175/JCLI-D-11-00709.1.

Lu, R.-Y., J.-H. Oh, and B.-J. Kim, 2002: A teleconnection pattern in upper-level meridional wind over the North African and Eurasian continent in summer. Tellus, 54, 44-55, https://doi.org/ 10.1034/j.1600-0870.2002.00248.x.

Luber, G., and M. McGeehin, 2008: Climate change and extreme heat events. Amer. J. Prev. Med., 35, 429-435, https://doi.org/ 10.1016/j.amepre.2008.08.021.

Lyon, B., and R. M. Dole, 1995: A diagnostic comparison of the 1980 and 1988 U.S. summer heat wave-droughts. J. Climate, $\mathbf{8}$, 1658-1675, https://doi.org/10.1175/1520-0442(1995)008<1658: ADCOTA $>2.0 . \mathrm{CO} ; 2$.

Meehl, G. A., F. Zwiers, J. Evans, T. Knutson, L. Mearns, and P. Whetton, 2000: Trends in extreme weather and climate events: Issues related to modeling extremes in projections of future climate change. Bull. Amer. Meteor. Soc., 81, 427-436, https://doi.org/ 10.1175/1520-0477(2000)081<0427:TIEWAC $>2.3 . C O ; 2$.

Mori, K., and T. Sato, 2014: Spatio-temporal variation of hightemperature events in Hokkaido, North Japan. J. Meteor. Soc. Japan, 92, 327-346, https://doi.org/10.2151/jmsj.2014404.

Murata, A., M. Nakano, S. Kanada, K. Kurihara, and H. Sasaki, 2012: Summertime temperature extremes over Japan in the late 21 st century projected by a high-resolution regional climate model. J. Meteor. Soc. Japan, 90A, 101-122, https:// doi.org/10.2151/jmsj.2012-A05.

Nakano, M., M. Matsueda, and M. Sugi, 2013: Future projections of heat waves around Japan simulated by CMIP3 and high- resolution Meteorological Research Institute atmospheric climate models. J. Geophys. Res. Atmos., 118, 3097-3109, https://doi.org/10.1002/jgrd.50260.

Park, C., and Y. Choi, 2012: Validation of quality control algorithms for temperature data of the republic of Korea (in Korean). Atmosphere, 22, 299-307.

Park, J.-K., W.-S. Jung, and E.-B. Kim, 2008: A study on the influence of extreme heat on daily mortality (in Korean). J. Korean Soc. Atmos. Environ., 24, 523-537, https://doi.org/ 10.5572/KOSAE.2008.24.5.523.

Schubert, S., H. Wang, and M. Suarez, 2011: Warm season subseasonal variability and climate extremes in the Northern Hemisphere: The role of stationary Rossby waves. J. Climate, 24, 4773-4792, https://doi.org/10.1175/JCLI-D-10-05035.1.

Takane, Y., and H. Kusaka, 2011: Formation mechanisms of the extreme high surface air temperature of $40.9^{\circ} \mathrm{C}$ observed in the Tokyo Metropolitan Area: Considerations of dynamic foehn and foehnlike wind. J. Appl. Meteor. Climatol., 50, 1827-1841, https://doi.org/10.1175/JAMC-D-10-05032.1.

_ - - and H. Kondo, 2014: Climatological study on mesoscale extreme high temperature events in the inland of the Tokyo Metropolitan Area, Japan, during the past 22 years. Int. J. Climatol., 34, 3926-3938, https://doi.org/ 10.1002/joc.3951.

Tan, J., Y. Zheng, G. Song, L. S. Kalkstein, A. J. Kalkstein, and X. Tang, 2007: Heat wave impacts on mortality in Shanghai, 1998 and 2003. Int. J. Biometeorol., 51, 193-200, https://doi.org/ 10.1007/s00484-006-0058-3.

Tao, S., and L. Chen, 1987: A review of recent research on the East Asian summer monsoon in China. Monsoon Meteorology, C.-P. Chang and T. N. Krishnamurti, Eds., Oxford University Press, 60-92.

Teng, H., G. Branstator, H. Wang, G. A. Meehl, and W. M. Washington, 2013: Probability of US heat waves affected by a subseasonal planetary wave pattern. Nat. Geosci., 6, 10561061, https://doi.org/10.1038/ngeo1988.

Wang, W., W. Zhou, X. Li, X. Wang, and D. Wang, 2016: Synopticscale characteristics and atmospheric controls of summer heat waves in China. Climate Dyn., 46, 2923-2941, https://doi.org/ 10.1007/s00382-015-2741-8.

Yeh, S., Y. Won, J. Hong, K. Lee, M. Kwon, K. Seo, and Y. Ham, 2018: The record-breaking heat wave in 2016 over South Korea and its physical mechanism. Mon. Wea. Rev., 146, 1463 1474, https://doi.org/10.1175/MWR-D-17-0205.1. 